\title{
LOS APROVECHAMIENTOS DE LA TIERRA EN ALCOY A FINES DEL SIGLO XIX
}

\author{
Emilia María Tonda Monllor
}

\section{RESUMEN}

Este trabajo tiene la intención de analizar algunos aspectos de Geografía Agraria localizados en el término municipal de Alcoy. En primer lugar se constatan una serie de datos globales referidos a la distribución superficial de los aprovechamientos de la tierra en lo que atañe a los terrenos cultivados como a los que no lo son (montes). Posteriormente se describen los distintos usos del suelo tanto en lo que concierne a los diferentes cultivos como a las utilidades forestales, incluyéndose una localización de todos ellos por partidas rurales.

Para la realización de este estudio se toman como base los años finales del siglo XIX aprovechando un a fuente de carácter fiscal como es el Amillaramiento o Padrón general de la riqueza inmueble, cultivos y ganadería... confeccionado en 1886, así como otros documentos relativos a esta temática que datan de esas fechas.

\section{RÉSUMÉ}

Ce travail a comme but d'analyser quelques aspects de la Geographie Agraire situés dans la municipalité d'Alcoy. On constate, d'abord une serie d'informations genérales sur la distribution superficielle des profits de la terre en ce qui concerne les terrains cultives comme ceux qui ne le sont pas (les monts). Ensuite en décrit les utilisations differentes du sol aussi bien les cultures variées que les exploitations forêstières, les situant par terroirs.

Pour faire cette ét ude on tient compte des dernières années du XIXéme siécle, utilisant une source de caractère fiscal comme le Cadastre ou Recensement général de la richesse mobilière, des cultures et elevages... elaboré en 1886, ainsi que d'autres doeuments relatifs à ce sujet et qui datent de cette époque. 


\section{Datos globales}

El término municipal de Alcoy posee una sup erficie total de 13.060 Ha, esto es, más de tres veces la extensión media de los municipios de la provincia de Alicante (4.188 Ha) correspondiente al 2'2\% del total de la provincia.

En el Amillaramiento de 1886 se contabilizan un total de $8.837^{\prime} 7$ Ha que se destinan a los diferentes aprovechamientos agrícolas y forestales, o sea, el 67'7 del total. El resto, 4.222'3 Ha, que corresponden al 32'3\% del valor absoluto municipal, no se contemplan en esta fuente, al tratarse de terrenos improductivos, casco urbano, caminos, etc...

Por lo que respecta a la superficie que se dedica a los diversos usos del suelo, el monte ocupa una gran proporción, el 47’37\%, y los cultivos el 52’7\% restante. De una manera global, para discernir cómo se encuentra aprovechado el terrazgo en Alcoy, hay que tener en cuenta la relación existente entre tierras cultivadas y tierras no cultivadas. En esos momentos, en 1886, el área no cultivada asciende a 8.406'9 Ha comprendiendo la de dedicación forestal más la considerada como improductiva, lo que se traduce en un 64’41\% de la extensión total. Además, la mitad de dichas hectáreas -exactamente 4.184'6- se encuentran ocupadas por monte alto, monte bajo y monte en general; el resto es considerado como terreno no productivo.

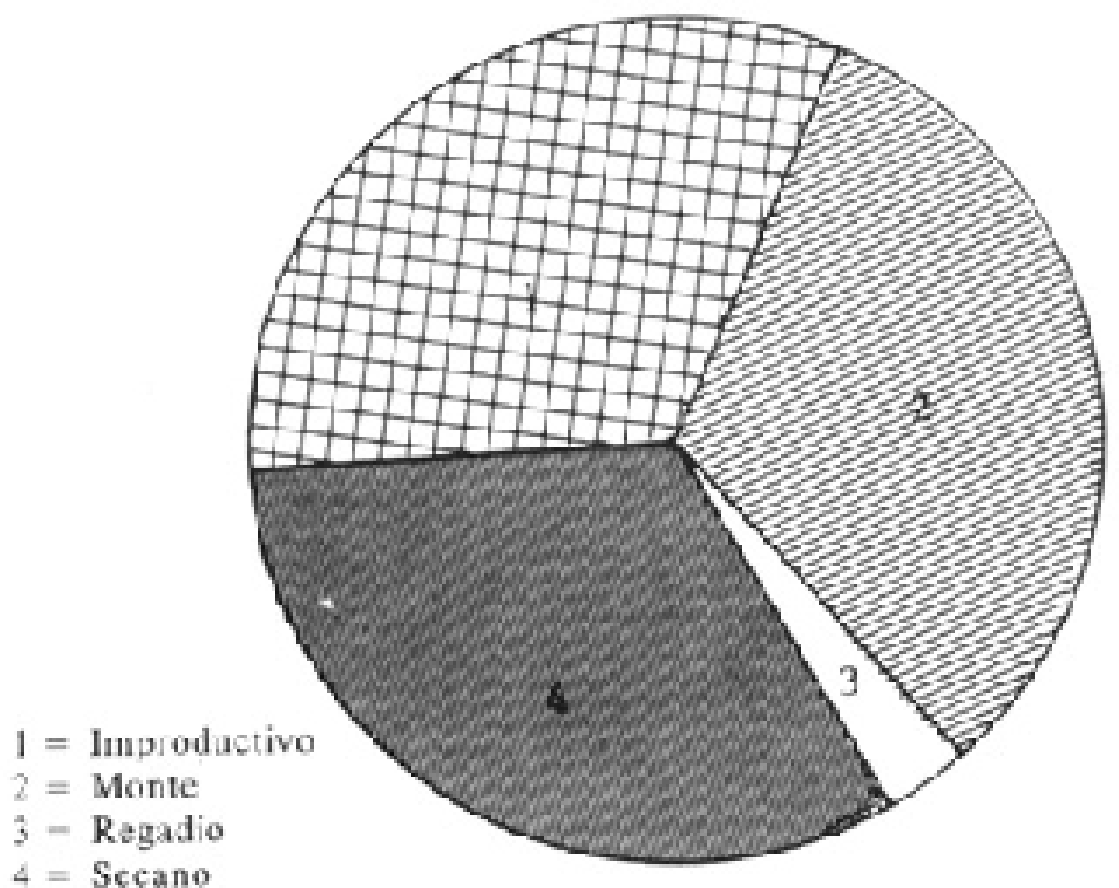

FIGURA 1. Distribución de la superficie municipal en 1886. 
Todos estos valores indican claramente que la utilización agrícola es bastante limitada debido a sus condicionamientos físicos, entre ellos la compleja y abrupta orografía a los que es necesario añadir la decidida y preferente vocación industrial, característica del término. El porcentaje que resta, el 35'6\% es superficie considerada como cultivada y comprende una extensión de $4.653 \mathrm{Ha}$, de las que 438’10 Ha corresponden al regadío y 4.219 Ha pertenecen a los cultivos de secano, esto es el 9'4\% y el 90’6\% respectivamente del total cultivado.

En el cuadro siguiente se distribuy en los diferentes ap rovechamientos en Alcoy a finales del Ochocientos.

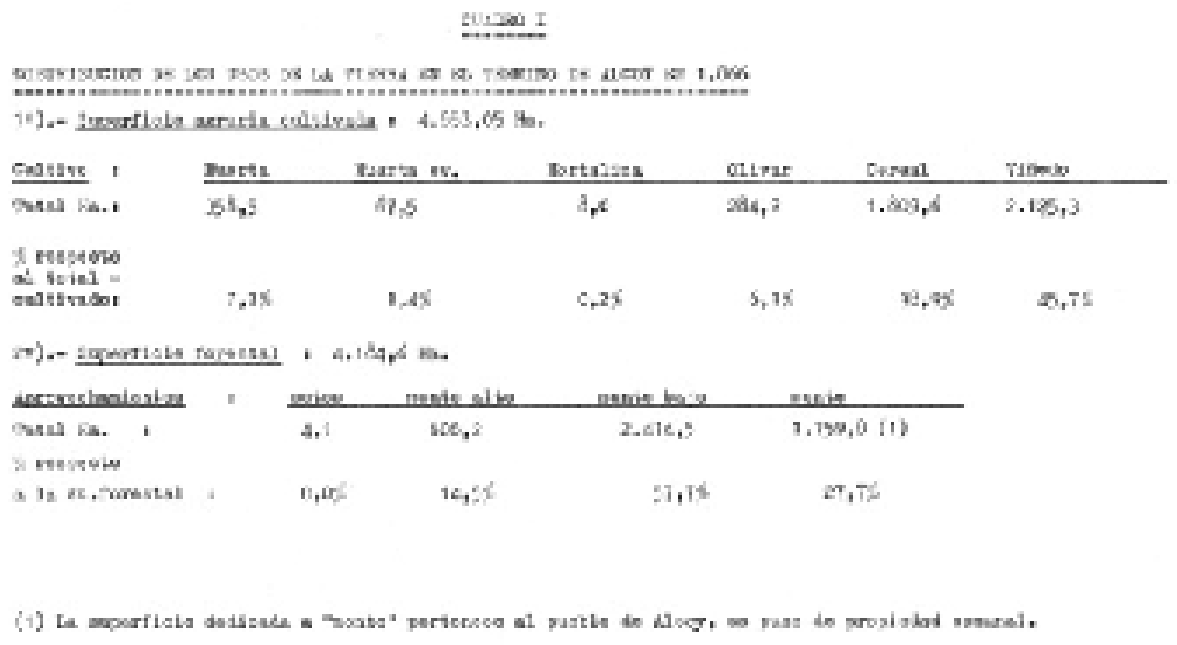

De los datos anteriores se desprende que los usos del suelo se reparten entre los agrícolas y los forestales con un ligero predominio de los primeros. Es necesario resaltar la supremacía absoluta de los cultivos de secano -cereales en año y vez, vid y olivo- sobre los de regadío. Estos últimos comprenden cuatro aprovechamientos, de distinta intensidad que en el Amillaramiento figuran con las denominaciones de «huerta» (dedicada a cereales y legumbres a la que se le prodiga el riego con agua de pie, de fuentes y riachuelos), «huerta eventual» (donde se practica este riego de forma ocasional) y las «hortalizas» que, junto con los «sotos» tienen una escasa importancia cuantitativa.

En los ap rovechamientos forestales destaca, siguiendo las denominaciones empleadas por el Amillaramiento, el «monte bajo», al que si se le añade el área de «monte», propiedad del común de vecinos y compuesta en su mayoría por matorral, conforman la formación vegetal esp ontánea predominante.

Por otro lado, el «monte alto» apenas supone el 15\% de toda la extensión montuosa. 


\section{Análisis de los principales aprovechamientos}

\section{Los cultivos}

La orientación agrícola del término estuvo condicionada por varios factores. Por una parte hechos de tip o físico como la climatología adversa a determinados cultivos y la accidentada topografía que ocasionaba una gran escasez de tierras arables al tiempo que dificultaba enormemente el transporte de determinados productos. Por otra el proceso industrial que se inició a mediados del Setecientos y que continuó a lo largo del siglo XIX motivó que los efectivos humanos se emplearan en las actividades de tipo fabril. Gran parte de esta mano de obra tenía una procedencia extracomarcal. Sin embargo este incremento de población no fue al unísono del desarrollo agrícola sino que, por el contrario, éste se manifestaba ya claramente insuficiente para el consumo interno, precisándose recurrir a importar una serie de productos de los pueblos de la comarca, sobre todo de aquéllos que eran básicos para el consumo cotidiano. De este modo ya desde fines del siglo XVIII se asiste a la dedicación de modo preferente hacia dos cultivos de cariz comercial como son la vid y el olivo, quedando la producción cerealista estancada. La explicación de esta orientación cultural debe buscarse en la existencia del gran mercado consumidor de Alcoy, así como en las peculiaridades del relieve, pues el terreno abrup to y las pendientes escarpadas obligaban al desarrollo de un cultivo en terrazas, que ofrece el aspecto de un abancalamiento en gradería, donde es impracticable el uso del arado, instrumento indispensable para el cultivo del trigo, en tanto que el viñedo y el olivar se adap tan mejor al aterrazamiento, pudiendo además su cultivo realizarse mediante la azada. Se añade la circunstancia de que los puertos de montaña que ponían en comunicación la llamada Foia d'Alcoi con las tierras circundantes, no permitían el paso a los carros y el transporte debía realizarse a lomo de caballerías por lo que el trigo y la harina podían llegar más fácilmente a la ciudad que el vino. De esta forma el cereal se traía de puntos más o menos lejanos mientras que la vid y el olivo se cultivaban in situ o cerca.

Al mismo tiempo las características climáticas de la zona se ajustan de forma clara al desarrollo de estos cultivos. La vid es un cultivo que resiste muy bien la sequía y que puede darse sin riego, al tiempo que es capaz de soportar un invierno crudo, condiciones que suelen presentarse en el área que nos ocupa. Por su parte el olivo se aclimata a los veranos secos sin practicarle regadío.

Por lo que se refiere a los cereales de invierno, el trigo era el que se daba prioritariamente. Aunque es poco exigente en calor, no puede madurar si el verano no es cálido y seco; sin embargo necesita humedad abundante durante el mes que precede y los días que siguen a su espigazón, cosa que ocurre en la primavera. Al mismo tiempo es un cereal que puede almacenarse en silos y graneros a fin de ser aprovechado en épocas de escasez. Se asociaba con cereales más pobres pero susceptibles de suministrar harina panificable, como el centeno, la cebada e incluso la avena. El primero de ellos presenta unas características similares al trigo, es más resistente al frío, tolerando además suelos pobres; la avena se diferencia por su exigencia y tolerancia a la humedad, empleándose 
en la rotación de cereales de invierno. Cuando el aumento demográfico obligaba a cultivar dos cereales de invierno éste se utiliza en rotación y como alimento del ganado. La cebada resiste mejor las sequías y es más precoz que los otros cereales y menos exigente en calor. El maíz se cultivaba en el término con resultados claramente insuficientes. Como cereal de verano, necesita temperaturas más altas y humedad, por lo que se le debía procurar el riego. En el término de Alcoy de temperaturas más bien bajas sobre todo en determinados años y la relativa escasez de la humedad, coadyuvó a una producción que no cubría las necesidades internas.

Las hortalizas presentan un comportamiento particular. Por tratarse de alimentos con carácter perecedero, aquéllas debían de producirse en las proximidades del núcleo poblacional pues eran consumidas en el mercado local. Por ser productos necesarios y de consumo en fresco, debían de cultivarse incluso en condiciones climáticas poco favorables pues el importarlas de otros lugares las encarecían notablemente, a lo que debe añadirse la enorme dificultad que suponía su transporte en un momento de considerable atraso técnico.

Entre los cultivos de secano destaca, en aquel entonces, la vid que ocupa casi la mitad de la superficie agrícola cultivada y de ésta el 57\% es calificada en el Amillaramiento como de tercera clase.

Este cultivo fue el más importante, sobre todo antes del desarrollo de la filoxera y especialmente con el boom de la demanda francesa de vino hacia 1880, lo que provocó su may or difusión. Este incremento debe asociarse también a la sustancial mejora acaecida en los medios de transp orte a partir de la segunda mitad del Ochocientos. A este respecto Piqueras Haba establece una clara conexión entre el tendido de la red ferroviaria, ocurrido en esos momentos, con la expansión vinícola ${ }^{1}$.

El Interrogatorio de 1848, detalla cómo se realizaba este cultivo². Las tierras de viña exigían las siguientes labores: se rompían por febrero y por mayo se le da otra labor y seguidamente eran cavadas las plantas quitando las malas hierbas. Asimismo se constata que la población alcoyana sólo p roducía vino tinto y sin otra clase de uva más que el llamado «morastell» o «monastrell». Este tipo de uva, aunque de escaso rendimiento, era la que mejor se adaptaba a las condiciones del terreno. No había cosecha de vino común blanco. Las tierras de viña se dividían en tres clases, de primera, segunda y tercera, que producían unas siete, cinco y tres arrobas de uva por hanegada, respectivamente. La vendimia se efectuaba en noviembre, la uva se pisaba en los lagares (los había en todas las casas de labor) y era estrujada luego a brazo, en prensas de madera de dos husos.

El Amillaramiento de 1886 designa con el epígrafe de «secano» a los aprovechamientos cerealícolas: trigo, maíz y cebada, a los que se destinaba el $40 \%$ del área cultivada en su mayor parte calificada como de tercera clase.

En el Interrogatorio de 1848, ya citado, se constata que en el secano las tierras de pan llevar se cultivaban un año si y otro no (rotación bienal de año y vez), se le daban cuatro labores hasta últimos de abril, época en que se sembraba el maíz.

Pérez Planelles cita entre otros cultivos, en mucha menor escala, el centeno y 
la avena ${ }^{3}$. En el trigo y el maíz, coincide con $\mathrm{Madoz}^{4}$ en afirmar que debían traerse de fuera, pues no eran suficientes para el abastecimiento interno.

$\mathrm{Al}$ olivo se le prop orcionaban labores semejantes a las de la vid; las aceitunas se recogían en enero y febrero y se llevaban a moler a las almazaras donde el rendimiento solía ser de 1/6 (una arroba de aceite por cada seis barchillas de aceitunas). El aceite debía también imp ortarse por ser su consumo may or que el que se produce. Las tierras que se dedicaban al olivo se califican de segunda clase sobre todo, aunque también está presente en las otras calidades en porcentajes similares (el 26\% es de primera clase, el 38\% de segunda y el 36\% de tercera).

La extensión dedicada a huerta estaba predominantemente calificada como de primera clase, aunque no se hallaba ausente en las demás calidades. Por Todos los Santos se le daba a las tierras dos labores previas para la siembra del trigo; por enero y parte de febrero se hacía una escarda y otra en el mes de mayo, se segaba a últimos de junio y a continuación tras una nueva labor y abonado se sembraba el maíz y habichuelas a los que se les prodigaban los riegos suficientes. Las habas y lentejas se sembraban por septiembre, se escardaban por febrero y se cogían en junio; los garbanzos y almortas se sembraban p or marzo, se escardaban por abril y se cogían por julio. También se daban algunas verduras y frutales.

Sin embargo, a pesar de este déficit agrícola Pérez Planelles atribuye, con probable exageración, una alta productividad, la may or -afirma- del País Valenciano, al campo alcoyano, hecho éste que el referido autor justifica porque la subdivisión de la propiedad exigía altos rendimientos que se lograban por el empleo de abonos y por la creación de suelos artificiales, construidos a base de tierra sup erpuesta a los terrenos pedregosos. "Y sin embargo -añade dicho autor- no se conoce Pueblo alguno de los de la provincia, cuy as tierras huertas, en igual cabida, produzcan tanto trigo, maíz y avichuelas (sic) constantemente todos los años, como las de Alcoy».

Cavanilles comenta «... multitud de huertas en anfiteatro», «... viendo por todas partes camp os bien cultivados a pesar de la desigualdad del terreno» y «... la industria de aquellos labradores, su talento y ardor han forzado la tierra a dar abundantes frutos» ${ }^{5}$.

Madoz, por su parte, constata «... las variadas producciones que cubren los campos de graderías», y al referirse a la partida de Horta Major afirma que «es la más preciosa del término de Alcoy y en ella se notan por el esmero y laboriosidad de los labradores las más variadas producciones, sucediéndose unas a otras sin interrup ción: todo está cultivado; nada hay que no sea huerta...».

Todos estos elogios evocan un terrazgo bien cultivado gracias al buen hacer de los labradores empeñados en lograr los máximos rendimientos a pesar de las limitaciones.

\section{Los usos, forestales y pecuarios}

En lo que se refiere a la sup erficie forestal cabe destacar que casi la mitad de la superficie amillarada se destina a los aprovechamientos de este tipo. 
En 1807, los bosques «son unos de realengo y otros de dueños particulares, pudiendo los vecinos romper las tierras incultas del término, que sólo son los pinares y carrascales, pues las demás están reducidas a cultivo, procediendo Licencia de la Real Marina y Establecimiento por parte del Real Patrimonio si el terreno es de realengo, que si es de particulares basta Licencia de la Marina»; así nos muestra Pérez Planelles la situación de los montes alcoy anos.

Pascual Madoz, describequeel término se encuentra cruzado por altísimas montañas, que forman una superficie áspera y desigual. La sierra de Mariola atraviesa el término de W a E y es el núcleo de los demás cerros, denominados al W San Cristófol, Sant Antoni; al N. Alberi, al S. Carrascal y otros. Constata el referido autor, que la vegetación es prodigiosa en los montes citados, a pesar de que el arbolado había decrecido sobre todo en el Carrascal, a consecuencia de los cortes de leña y madera que constituían la materia prima para las fábricas de la ciudad (tintes y papel), hasta el extremo de que los pueblos cercanos debían venderles su propia leña.

Por un oficio de trece de noviembre de 1863 se desprende que, entre los montes vinculados al Ayuntamiento de Alcoy, los únicos que habían sido vendidos eran los denominados Canelons y Comellars, de reducida extensión y enteramente calvos, así como el Carrascal, aunque de éste se reservó el coto de la Font Roja como de ap rovechamiento común, que era precisamente la parte más poblada de árboles. También por entonces son montes públicos del municipio los de Sant Antoni y Sant Cristófol, que poseía el Estado y que a reclamación de dicho Ayuntamiento le fueron restituidos por Real orden de 3 de noviembre de 1862, siendo la extensión aforada del primero 160 Ha y 120 la del segundo; por último también era de propios el conocido con el nombre de Els Plans, cuy a cabida excedía notablemente a la de los anteriores y cuyos pastos eran codiciados en verano. El aprovechamiento de todos ellos, unido al de los vastos eriales de libre entrada que poseía el Real Patrimonio en este término, concede a los ganaderos la utilización de los mismos. Para la conservación de estos montes existían tres guardas.

Por un documento fechado en marzo de $1842^{6}$ se sabe que los terrenos para pastos y del común habían disminuido notoriamente debido a las arbitrariedades llevadas a cabo por los vecinos cercanos al término, como era el caso de las roturaciones efectuadas de manera encubierta o clandestina. Esto dificultaba la ganadería ya que algunos particulares se apropiaron de muchos trozos de Montes Realengos o Nacionales, sin darse cuenta de que se necesitaban como sostén del ganado. Estos particulares ensancharon sus heredades sin haber obtenido el op ortuno Establecimiento en legal toma.

Así y por otro documento que data del 23 de noviembre de $1844^{7}$, se insta a una serie de propietarios que roturaron algunos terrenos de realengo sin ser dueños legalmente a que los abandonen, dejándolos al beneficio común, sembrándolos antes de bellotas, pinos o de otras semillas adecuadas tantas veces como hay an incumplido las Reales Ordenes. Así mismo en el Boletín Oficial de la Provincia de Alicante de igual fecha (noviembre 1844) se hace un llamamiento a los distintos Ayuntamientos para que se respeten al máximo los derechos de los ganaderos, fijando de manera precisa los lugares que son de la comunidad ${ }^{8}$. 
De esta forma los dueños de las heredades debían limitarse a cultivar el número de jornales establecidos o peytados, dejando a beneficio del público aquella parte del terreno realengo que ocupaban sin justo título. Todo esto se llevaba a cabo con la finalidad de que los pastores y leñadores conocieran los sitios donde pueden apacentar sus ganados y arrancar leña como cosa pública o del común y en que lugares les está vetado por ser de dominio particular. Por ello los labradores y ganaderos se plantearon la necesidad de establecer unas Ordenanzas, denominadas de «La Tabla» para la realización de tal deslinde ${ }^{9}$.

Al mismo tiemp o se concedían permisos a los ganaderos de los pueblos limítrofres ${ }^{10}$, para que utilizasen los pastos del término, previo pago de una cierta cantidad de dinero, un cuartillo de real por res, aunque surgieron quejas ya que en muchos pueblos limítrofes no existía esa reciprocidad. Se aprobó no expedir licencia alguna más que a los ganados de aquellos pueblos que hicieran igual concesión a los de la ciudad de Alcoy ${ }^{11}$, tal como sucedió en el municipio de Penáguila.

En aquellos momentos son constantes las peticiones que los ganaderos hacen al Ayuntamiento para que tenga en cuenta la escasez de pastos. Exp onen que desde inmemorial hasta la fecha de su demanda en 1843, podían entrar libremente al Carrascal, sin pago alguno, pero el Ayuntamiento ha estipulado el que se pague un real por cabeza así como la prohibición de entrar a pastar en dicho monte por cuanto se daña el arbolado allí existente. Por su parte los ganaderos sostienen que el ganado lanar se alimenta de una hierba que no sirve para nada, el marfull(Viburnum tinus), y que la referida decisión les afecta en gran manera. De esta forma se ven en la necesidad de arrendar cotos en otros lugares, caso de Tibi, por lo que solicitan sitios para llevar sus ganados. Siguen las peticiones en el sentido de que se mantengan las mancomunidades de pastos entre Ibi y Alcoy, a lo que la Comisión de Montes accede previo pago de un real de vellón anual por cabeza, cantidad igual a la que pagan los vecinos de Alcoy.

Así pues, las tierras que no son aprovechadas para la agricultura por su accidentada top ografía, alimentan una ganadería de tip o extensivo que consume el pasto existente en estos camp os sin cultivos o bien con residuos de ellos, es decir, rastrojos de cereales. Los pastos de invierno suelen ser de cierta calidad, mientras que en verano se utilizan las partes bajas.

El tipo de ganado que se consigna en el Amillaramiento viene referido como caballerías may ores y menores esto es el ganado mular y asnal, se trata pues de ganado de labor. El empleo de la mula como trabajo de la tierra se explica por ser un instrumento de trabajo muy barato que requiere pocos cuidados y que es al mismo tiempo muy resistente. La clase de ganado se encuentra también en relación con el tipo de cultivo donde se utiliza, intensivo o extensivo, y con el tamaño de la propiedad a explotar. De este modo en los cultivos extensivos y en la pequeña propiedad, ambos prioritarios en el término, la mula y el asno son los más generalizados. Por el contrario el empleo del caballo, más rápido, lo es en cultivos de carácter intensivo, escasos en el término, lo que se confirma por su reducido número en la zona.

El ganado de renta es en su totalidad de la especie ovina. La mayoría de sus 
dueños no sobrepasan las 10 cabezas, constatándose el hecho de que muchos son al mismo tiemp o arrendadores que trabajan la tierra a otros.

Existen varias descripciones de las vías pecuarias que recorrían el término ${ }^{12}$. Según una guía de Alcoy de 1925 el término era surcado por cuatro cañadas y seis veredas. La primera de estas cañadas iría desde Cocentaina a Torremanzanas; la segunda desde Bocairente a Ibi; la tercera desde Bocairente a Torremanzanas y la cuarta desde Jijona a Ibi y sale a Bocairente ${ }^{13}$.

\section{Distribución espacial de los aprovechamientos por partidas rurales}

Atendiendo a la localización en las diferentes partidas rurales el mayor porcentaje de viñedo está presente en aquellas más alejadas del núcleo urbano, predominando en Polop Alt y Polop Baix, así como en Barxell y Canal Alta y Baixa que reúnen el 60`5\% de toda la superficie destinada a la vid. Si a éstas les sumamos las de Mariola, Llacunes y Regadíu, que también p oseen una localización circundante al núcleo poblacional, el p orcentaje se eleva al $81 \%$ de toda la vid alcoy ana.

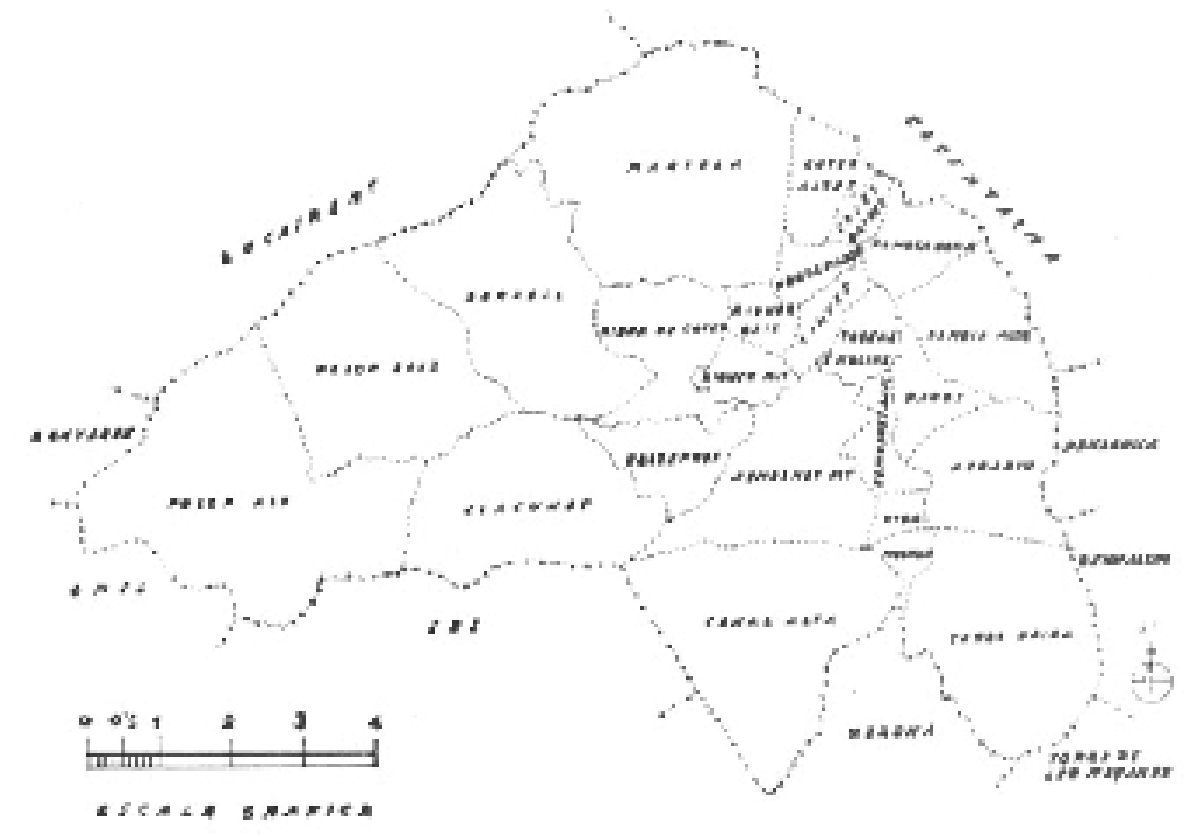

FIGURA 2. Alcoy. Localización de las partidas rurales

En el cuadro siguiente se reflejan los porcentajes de los distintos ap rovechamientos por partidas rurales en relación a cada cultivo. 
quas.:.1

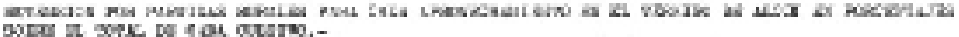

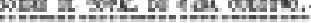

\begin{tabular}{|c|c|c|c|c|c|c|c|}
\hline pariten & renate & $\operatorname{cosen}$ & enerenc $\quad 6-$ ? & pifa & F,xis & X.tade & mants \\
\hline larall & 14,4 & $a, D$ & $\gamma=$ & 12,1 & 48 & $\operatorname{lint}$ & - \\
\hline Denel acta & 0,1 & 4,1 & 12,9 & 95 & $15 \delta$ & 1,4 & - \\
\hline Inwal kates & - & 9,9 & 10,5 & 6,2 & $1: .1$ & 2.1 & 6,6 \\
\hline Sotten Dtor & 8,0 & 19,9 & $1+2$ & 135 & - & $1 r$ & - \\
\hline Pahe Baixry & 12.1 & 3,3 & 8.6 & A. 3 & $\$ 4$ & & - \\
\hline wirie eagur & $12, \mathrm{n}$ & 7,6 & تهد & $4=$ & - & $\Delta, 3$ & - \\
\hline hasurn! & 2,2 & 3,6 & $5+2$ & $T, 1$ & 14.2 & 3,3 & 15,1 \\
\hline Zurinas. & $a p$ & 6,0 & int & 4,6 & $1 s, \varepsilon$ & $3 e^{4}$ & 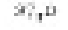 \\
\hline Wolivere & 1,1 & 4.5 & $1+2$ & 0,7 & - & - & - \\
\hline Ragere & 2.0 & 2,5 & $t .1$ & 1,3 & 9,4 & 1.2 & - \\
\hline Notup a 15 & 1,4 & $e, n$ & $-4,3$ & 157 & $10 . d$ & 30 & - \\
\hline falop batx & 3,0 & 9,3 & 1,1 & $15=$ & $1:, 4$ & 13.7 & - \\
\hline 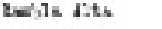 & 2,1 & 4,0 & 4,7 & 39 & $D, A$ & 10 & - \\
\hline taisle latea & $s, T$ & $-\quad 2,4$ & $i n$ & 0,8 & - & - & $-=$ \\
\hline 3apadac & - & 1,4 & 5 & 6.2 & 4,6 & int & - \\
\hline $16=$ & 0,0 & - & - & $4=$ & - & $=$ & $=$ \\
\hline sigee A:2 & 6,0 & 2,2 & 1,0 & 1,1 & 8,0 & 9,6 & - \\
\hline zinore and $x$ & 14,5 & $<, 9$ & $v, t$ & 6, & $=$ & - & - \\
\hline Salv & 4,8 & 2,1 & 3,14 & 45 & 9,0 & 1,6 & = \\
\hline 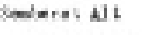 & 6.0 & 3,4 & 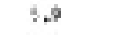 & 3 & 3,8 & 10,4 & 29,3 \\
\hline inderert mix & 9,1 & 5,6 & $2,2^{2}$ & $a, 5$ & $=$ & $=$ & $=$ \\
\hline Fimen & 0,0 & - & - & - & - & - & - \\
\hline Tweod o Mukan & 8.0 & 0,0 & 0.1 & - & - & - & - \\
\hline גבזט & 0,3 & - & $6, \mathrm{n}$ & $=$ & $=$ & - & - \\
\hline Sin momodinar & 1,2 & 0,3 & 0.2 & $=, c$ & $0, T$ & $\hat{A}, 0$ & - \\
\hline Potales & $96, \mathrm{~b}$ & 500,8 & $1: 4,5$ & $7 \%$ & bog, 8 & 106.0 & $16 \%, \pi$ \\
\hline
\end{tabular}

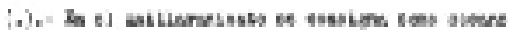

El trigo se cultivaba tanto en las huertas como en los secanos. Se encontraba en regadíos como Barxell, Polop Alt y Baix y en Mariola. La extensión en superficie de este cereal fue la de may or imp ortancia, circunstancia ésta que no impidió el que fuese deficitario en su producción. Los demás cereales -Cebada, avena y maíz-se daban igualmente en las partidas ya referidas para el trigo. La dedicación cerealista en estas tierras de secano, pobres en general, agotaba su fertilidad, lo cual obligaba a mantenerlas periódicamente en barbecho. Dicho sistema era utilizado comúnmente en Polop, La Canal y Riba.

El olivo se encontraba con frecuencia asociado a otras especies como la vid, capaz de soportar temperaturas bajas, mientras que el olivar se localizaba de modo preferente en las solanas montañosas del término, mediante el abancalamiento de las vertientes. Predominaba en Cotes Altes y Baixes, partidas que rodean el casco urbano. También Polop Baix contaba con la 
presencia de la oleaginosa, así como Barxell, Mariola, Sembenet Alt y Baix. Todas las partidas citadas concentraban el 61'5\% del total. Por tratarse de un cultivo poco exigente en trabajo, muchos agricultores alternaban su cuidado con la dedicación a las labores hortícolas, de ahí que su ap rovechamiento sea de tercer orden.

Las tierras regadas de hortalizas y frutales, poseían aún menor significación espacial que el olivo. Su misión princip al consistía en abastecer al núcleo urbano en régimen de autoconsumo. Sin embargo hay que precisar la importancia relativa que adquieren en lo que respecta a su alta cotización pues a una hanegada de huerta de primera clase se le evaluaba en el Amillaramiento un producto de 43'8 pesetas. En comparación con los otros cultivos, la hanegada de primera clase se cotizaba para el olivar a 9'5 pesetas, para el grano a 8'2 y para la viña a 7’5 pesetas. Como se aprecia la hanegada de huerta cuadriplicaba ampliamente el valor de la del olivar, que era la tierra de secano mejor valorada. Así pues el producto líquido varía dependiendo de su clasificación como secano o regadío y también por el tip o de cultivo implantado en el terreno.

Los aprovechamientos hortícolas se localizaban de modo preferente en Horta Major, partida que hoy casi se confunde con el mismo núcleo de población, ya que por tratarse de productos perecederos y debido a la mala conservación de los caminos, requerían situarse en el mercado urbano con rapidez. A pesar de ello se encontraban en otras partidas con el fin de aprovechar su riqueza en recursos hídricos. Tal era el caso de Barxell, Cotes, Riquer y Polop Baix o de las del Salt, Sembenet Baix y Rambla Baixa que aprovechan respectivamente las aguas del Barxell, las del Molinar o las cercanías a la Horta Major.

Por lo que respecta al área dedicada al monte, en las partidas de Canal Baixa, Llacunes, Mariola y Sembenet Alt, se localizaban las áreas forestales que eran propiedad del común de vecinos. El monte bajo se localizaba con preferencia en Barxell, Canal Baixa, Mariola, Polop Baix y Sembenet Alt. El monte alto estaba presente además de en las partidas citadas en Canal Alta, Llacunes y Polop Alt. El porcentaje de monte era escaso en Riquer Baix y Rambla Baixa, partidas que están próximas a la ciudad.

En la figura 3 se representan gráficamente la distribución en los usos de la tierra de algunas partidas rurales. Se han seleccionado éstas p or ser representativas en la localización de los princip ales ap rovechamientos, como la vid que es predominante en la partida de Polop Alt, el monte en Mariola, la huerta en Horta Major, y el cereal en la de Canal Alta.

Hay que precisar que en el regadío se han agrupado los aprovechamientos de huerta, huerta eventual, hortalizas y sotos (fig. 3).

Hay que considerar que las mejores tierras de cultivo se encontraban entre el río Barxell y las estribaciones de Mariola, donde estaban los regadíos de Riquer, Uxola y Cotes, que aprovechaban los ap ortes de escorrentía que descendían de la Sierra de Mariola o de las aguas hip ogeas que manaban de la fuente de Barxell dando lugar a l'Horta Major de la villa.

Las tierras cualitativamente menos rentables eran aquéllas que rodean las montañas que limitan la Foia d'Alcoi por el sur y sudeste como Salterres y Llacunes, donde predominaban los aprovechamientos de tipo forestal así como 


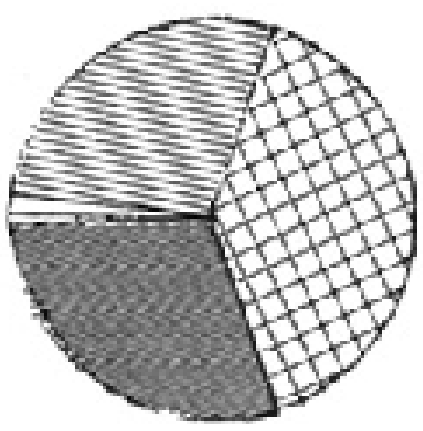

Polop Alt

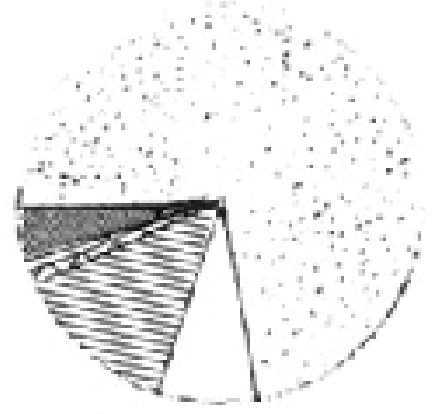

Horta Major

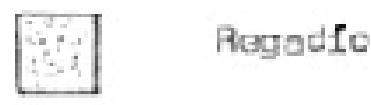

0livar

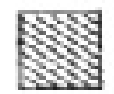

Geceno
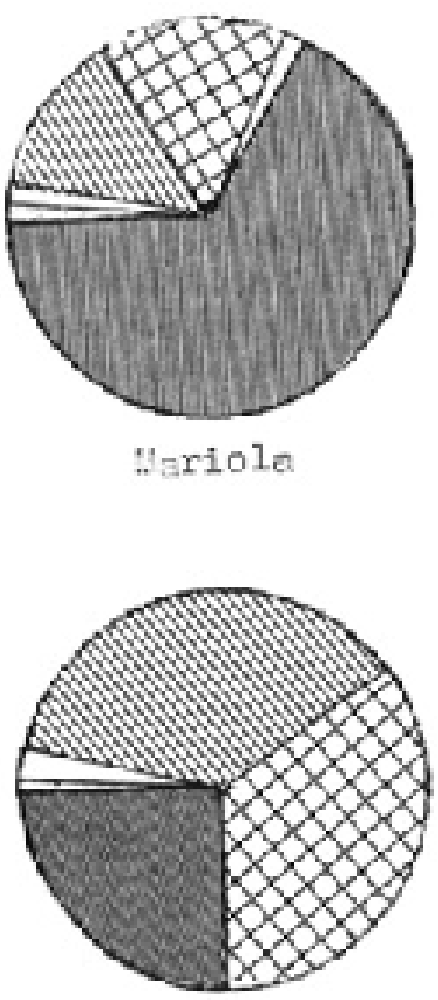

Cenal Alta

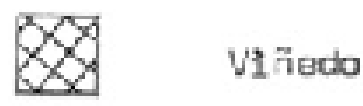

bionte

FIGURA 3. Tipos de distribución en los aprovechamientos de la tierra en algunas partidas rurales. 
los relieves tabulares de la Rambla Alta, que desde la Serreta y Ull del Moro bajan hacia el cauce del Molinar y Barxell.

El área montuosa era prioritaria en algunas partidas. Caso de Mariola donde suponía el 69\% de todos los aprovechamientos, existiendo allí además el monte de San Cristófol. En Canal Baixa el porcentaje era del 59\%, destacando entre las superficies arbóreas Els Plans. En Llacunes el porcentaje era del 60’3\% con el Carrascal o Font Roja y Sembenet Alt, con un 80\% y que cuenta con el monte de Sant Antoni. Todos estos montes suman una superficie de 1.160 Ha y pertenecen al pueblo de Alcoy .

Por último existían una serie de partidas que no tenían propiamente un carácter rural, como eran las de Riba, Tossal y Molins, Tintes y Molinar que eran esencialmente fabriles. Todas ellas son contiguas y surcadas por el río Molinar, utilizado como fuerza motriz para el movimiento de los distintos artefactos o establecimientos de carácter industrial.

\section{NOTAS BIBLIOGRÁFICAS}

1 PIQUERAS HABA, J. La vid y el vino en el País Valenciano. Valencia, Instituto Alfonso el Magnánimo, 1981, pp. 52-55.

2 (A)RCHIVO (M)UNICIPAL (A)LCOY,Interrogatorio quedirigeelComisionado Regio de Agricultura de la Provincia de Alicante a Alcoy. Año 1848. Sección Fomento.

3 PÉREZ PLANELLES, F. Plan estadístico de la villa de Alcoy (20 de junio de 1807), Ayuntamiento de Alcoy, Sección de Geografía de la Universidad de Valencia, 1983, p. 29.

4 MADOZ, P. Diccionario Geográfico-estadístico-Histórico de España y sus posesiones de Ultramar, T. 1, art. «Alcoy», Madrid 1846, p. 474.

5 CAVANILLES, A. J. Observaciones sobre la Historia Natural, Geografía, Agricultura, Población y Frutos del Reino de Valencia, Madrid, 1795-1797, ed. facsímil, Soler, Valencia, 1972, II, pp. 192-193.

6 A. M. A. Azagadores y montes realengos. Petición de varios cortantes y pastores para su deslinde. Año 1842.

7 A. M. A. Azagadores y montes realengos. Juan Laliga y otros peticionarios sobre deslinde de azagadores y montes realengos. Año 1844.

8 A. M. A. Boletín Oficial de la Provincia de Alicante. 6 de noviembre de 1844, núm. 74, circular núm. 307.

9 TONDA MONLLOR, E. M. ${ }^{\text {a }}$ La estructura agraria y los cultivos del término municipal de Alcoy, según el Amillaramiento de 1886; Tesis de Licenciatura, inédita, Univ. de Alicante, 1987, 614 pp., en pp. 520-528.

10 A. M. A. Expediente sobre mancomunidad de pastos entre Ibi y Alcoy, Año 1843, Legajo 1. ${ }^{\circ}$, núm. 23.

11 A. M. A. Pastos comunes. Año 1844, Sección Fomento.

12 A. M. A. Azagadores y montes realengos. Juan Laliga. MINISTERIO DE AGRICULTURA e ICONA, Proyecto de clasificación de las vías pecuarias existentes en el término municipal de Alcoy, Provincia de Alicante, sección Vías Pecuarias. Realizado por el Perito Agrícola del Estado, D. Ricardo López 
de Merlo quien recopiló datos y planos antiguos, por lo que las citadas vías son las que se han venido usando desde inmemorial. Está fechado en 1973. Vid. también, TONDA

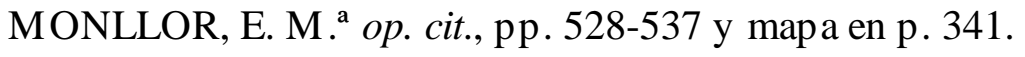

13 VICEDO SANFELIPE, R. Guía de Alcoy, Alcoy, Imp. El Serpis, 1925, p. 17. 